\title{
Current Trends and the Consequences of Research Activities among Chinese Universities
}

\author{
Silohenda Hileni Amuthenu \\ Institute of International and Comparative Education, Beijing Normal University, Beijing, China \\ Email: silo3030@gmail.com
}

How to cite this paper: Amuthenu, S.H. (2019) Current Trends and the Consequences of Research Activities among Chinese Universities. Open Access Library Journal, 6: e5847.

https://doi.org/10.4236/oalib.1105847

Received: October 11, 2019

Accepted: November 17, 2019

Published: November 20, 2019

Copyright $\odot 2019$ by author(s) and Open Access Library Inc.

This work is licensed under the Creative Commons Attribution International License (CC BY 4.0).

http://creativecommons.org/licenses/by/4.0/ (c) (i) Open Access

\begin{abstract}
China continues to be one of the world's largest producers of academic research papers contributing massively to national and international journals annually. To maintain such a position, the government put up policies and practices to ensure that actors and all universities engage in research activities. However, this initiative which was initially aimed at motivating and encouraging research participation seems to be pressuring researchers. Hence, this study employed a qualitative approach to extensively review existing literature to determine the current research trends and the consequences of the pressure to engage in research activities among Chinese top-rated universities. Using a Skinner's operant conditioning theory, the study found out that China's research activities have significantly improved, however, it may be to a cost of research misconduct as well as negligence of other academic activities of equal importance. This study recommends a new approach that promotes and adds to the current ethical research activities and brings about a paradigm shift from quantity to quality research publications for professional evaluation purposes.
\end{abstract}

\section{Subject Areas \\ Education, Sociology}

\section{Keywords}

Higher Education, Research Activities, Research Misconducts, Professional Assessments and Evaluations, China Top Ranked Universities

\section{Introduction}

Among the three key functions of higher education institutions, recent literature points that Research and innovation are been valued and given priority since $20^{\text {th }}$ 
century in comparison to Teaching and Learning and Community Engagement [1] across the world. In China, since the opening up to the outside world, research was proclaimed to be the major function of all universities with the government pronouncing "universities to be education centers and research centers" [2].

Whether a university is research-oriented or not, the pressure for academics to carry out research and publish the findings seems similar both in public and private universities. Such pressure in academia to rapidly and continually publish academic work to sustain or further one's career is described as "publish or perish" [3]. Although the publish or perish philosophy came from America it has evidently spread to other countries including China.

The importance of research cannot be overemphasized as [2] asserts that research and innovation create codified knowledge for higher education institutions in the forms of publications, patents, and prototype, and also help institutions to contribute to the local and national economies through research commercialization, problem-solving, and by providing public space especially for developing nations.

[4] argues that universities in developing countries such as China have a bigger role to play when compared to higher learning institutions in developed nations. Their role is to conduct research that contributes to the technological development and industrial performance, with diverse interfaces between research institutions and the commercial sector. [2] echoes that "the development of research in higher education institutions is of vital importance for fulfilling the national strategy of rejuvenating China through science and education", further linked research to the improvement of higher education.

Currently, the output of research and innovation has been used as tools for administrative purposes of performance when ranking institutions and promoting individuals [5] [6]. A study carried out by [7] reveals that the chances of one to be recruited depend heavily on the number of publications in the selected list of journals relevant to the discipline the individual has or signed to have at the end of the contract. [8] adds that research does not only predict the individual career success it also measures the quality of an institution. Although the argument seems broad it is reasonable to think that research could be used to inform the teaching and learning therefore, improving the quality of education being offered.

[7] stressed that Chinese academics are pressured to publish in both local and internationally indexed journals with the pressure being exerted more to intertional indexed journals.

[9] warns against exerting pressure on researchers to publish in certain journals because it may lead to negative consequences giving an example of the United Kingdom (UK) where tools such as Assessment Exercise and Research Evaluation Framework are used to assess research productivity and are largely characterized by counting numbers of recognized publications. However, such 
actions come at the expense of innovation and quality papers. Similarly, in the United States of America (USA) the same philosophy has led to the questioning of the quality of research outputs, and it has further led to the negligence of other academic activities, including teaching and learning as most academics devote most of their time to research activities.

[7] states that the "publish or perish" philosophy is relatively new this is evident from studies related to Publish-or-Perish discourses in China which have received little empirical investigation thus far, hence this study aims to contribute to the investigations pertaining to research activities in China. It particularly looks at the current trends in research as well as the consequences of the "Publish or Perish philosophy" in China. This study acknowledges that there are independent research institutes outside the higher education institutions for example, the Chinese Academy of Social Sciences centers [2] or research institutions of line ministries or industries, however this study focuses on research activities of universities. Firstly because research carried out in universities has its own unique features, researchers in higher education institutions have multiple tasks such as teaching and learning, community involvement and it may be challenging to balance these big roles of similar importance, unlike research centers where researchers are full-time researchers without other responsibilities. Secondly, research in higher learning institutions aims at contributing to knowledge creation and distribution. [2] states that in higher education institutions "knowledge is created and by research, distributed by teaching and applied through community engagement", hence, it creates a circle of knowledge production (p.175) which makes a significant difference in the society.

Apart from the above section which is the introductory chapter, the rest of the paper is organized into 4 other sections; Chapter 2 presents the literature review, Section 3 describes the methodology that was used, Section 4 presents the findings and discussions and the last section is the conclusions and recommendations.

\section{Statement of Problem}

Just like any other country, China continues to boost its research production. The government and universities use publications in peer-reviewed journals as an important benchmark to evaluate the performance of all researchers, this subsequently affects their salaries, funding applications as well as promotion. The emphasis is placed often on internationally-indexed journals in order for the country to be able to compete with the rest of the world. Literature establishes that as much as such policies and practices bring about significant improvement in research activities it is to a cost of research misconduct as well as negligence of other academic activities of equal importance. Hence, this study aims to explore the current trends of research among Chinese universities and the consequences of the enormous pressure exerted on institutions and actors within institutions in particular as they persevere in their careers. 


\section{Research Questions}

This study aims to answer the following research questions:

1) What are the current trends of research activities among academic staff in Chinese top-rated universities?

2) What are the consequences of pressuring academics to conduct research and publish in internationally-indexed journals?

\section{Significance of the Study}

An exploratory study on Chinese research trends and the consequences experienced as a result of pressuring for more publications is of significance as it informs on the status quo in terms of research and subsequently allows one to predict the future research directions of the country. In addition, it allows for solutions to be suggested with regards to the pressure being exerted upon academics. For a comparative grip, the study is of great significance in understanding the educational processes and practices of other nations in order to evaluate one's own research trends and consequences as an indicator of global economic competitiveness as well as to learn from other nations' policies and educational practices in order to improve one's own.

\section{Definition of Terms}

Academic Research: creative and systematic work undertaken to increase the stock of knowledge, including knowledge of humans, culture, and society, and the use of this stock of knowledge to devise new applications conducted by academic staff at the institutions of higher learning in China.

Higher learning institutions: Chinese post-secondary education that offers higher qualifications.

\section{Materials and Methods}

\subsection{China Higher Education Context}

China currently has the largest education system in the world [10] [11]. Since the People's Republic of China (PRC) was founded in 1949, China's higher education sector has experienced high enrollments. For example, in 1949, the Chinese higher education sector was small with just 205 institutions, majority of which were publicly owned, and few to none private universities according to the China Education Yearbook quoted by [12] and the figures keep rising up.

The government as the overall overseer of higher education provides funds for all institutions. The funding process is described by [2] to below by then. However, after the universities were restructured into 3 categories namely; 1) teaching institutions; 2) teaching research institutions; and 3) research institutions, higher institutions were informed that a greater proportion of their operating funds would be derived from sources other than the government. That meant that for teaching institutions, the source of funds was to be tuition fees paid by students or finance from other sectors of the economy. While for re- 
search-oriented universities, funds were to be derived from money generated from their research and development funds. The funds for research in Chinese universities derived from the government fell from $75 \%$ to $43 \%$ between the period of 1985 to 1995 [13]. There has been an unequal distribution of funds based on the type of research particularly applied research has been recently getting a bigger share of the funds in comparison to basic and development research. The funds rose between 2004 and 2006 however, the percentage of funds derived from the government remained constant around 55\%, and of recent, funds from private sectors have been changing depending on the economic status. In 1985 the research force of higher education institutions was very weak as described by [2] due to limited research personnel in higher education. However, there has been a gradual increase, due to a reform of the personnel system in the higher education system, and teachers' enthusiasm in conducting research as well. As of 2005, there were only 1792 universities and colleges, of which 678 have Research \& Development (R \& D) activities. Of these, 49 have science parks and host 95 State Key Labs, and 59 have graduate schools.

Academics and students have been scooping awards for leading force research and innovations ever since 2000 in their disciplines [2]. About two-thirds of total $\mathrm{R} \& \mathrm{D}$ expenditure in the higher education sector is concentrated on the top 50 universities. A few top universities such as Tsinghua and Peking University are strong in both research and entrepreneurial activities. They are active in creating their own enterprises, science parks, transferring technological results, and establishing links with industries and local government.

As China is experiencing rapid economic growth and comprehensive social transformation, it subsequently has direct effects on its education system at the national level. The Department of Policies and Regulations in the Ministry of Education is in charge of educational reform policies and strategies, including the research and survey of relevant issues. Hence, the higher education institutions have to keep a balance between the two tasks and at the same time combine them by including students, especially undergraduates in the process of research and embodying the research achievements. In most institutions, research publications are boosted by the postgraduates' researches. [2] echoes that one-third of the research works are conducted by postgraduates. This ratio could have increased due to the increment of postgraduates students in recent years.

\subsection{Research Centers}

Apart from the higher education institutions carrying out research, there are other research centers created for research purposes [2]. Most of them are linked to the line ministries, for example within the line ministry of education there are about 3 research institutions directly affiliated to it namely 1) the National Institution of Education Sciences, it researches on issues related to education, thereby leading important educational topics and policy-making; 2) the National Centre for School Curriculum and Textbook Development; and 3) The National Education Examinations Authority of the Ministry of Education, which focuses 
on examination. This is similar to other ministries as well.

It is worth noting that even at local government level, there is also an educational research institution, which focuses more on curriculum and pedagogy while at the grassroots, and every school has a "teaching study group" of which some are very active others are not [2]. Active groups play an important role in educational research as their contributions are practically based on experienced.

\subsection{China Management of Research Funding and Achievements}

Literature shows that equal distribution of research funding is a challenge that is not unique to China. China has instituted measures such as application and examinations, which guide the system to ensure that state funds are allocated to researchers whose research directly addresses the needs of the country. Furthermore, the system also guides against the self-allocation of resources, self-satisfaction type of assessment, and self-recycling of research production [2]. The achievements or awards gained from the research, is shared by "the university and the researchers" (p. 179) based on policies instituted by the government. These policies motivate most higher education institutions as well as researchers to publish their research outcome.

It is worth noting that in most cases, language serves as a major barrier to research in China; for example, much of the current research is published in Mandarin which means that most of the current scientific development in China is not readily available to non-Chinese-speaking scientists. Nonetheless, few works and abstracts of papers are in English.

\subsection{A Comparative Grip of Research International Trends in the OECD Countries}

Without doubt, there has been significant growth in research and development among OECD countries in the last two decades [14]. The OECD report further explained that such an increase accounts for about $80 \%$ of all research and development expenditures in the world [10].

Although the funding varies across countries, most of the research and development carried in OECD countries are funded by the business sector. This indicates that business expenditures on research continue to rise, and is reported as one of the most significant trends in the last decade. On the contrary, countries such as Greece, Poland, Portugal, and Turkey, were funded by higher education institutions [14].

The report showed a relative decline in government participation in funding research and development. The government-funded $\mathrm{R} \& \mathrm{D}$ decreased from $0.85 \%$ to $0.68 \%$ of GDP, and the percentage of total R \& D financed by the government, from $40 \%$ to $30.4 \%$ [10].

This funding decline can be considered relative since in real terms, government expenditures have actually increased by $60 \%$ since 1981 . The share of government military R \& D has however showed a significant decrease between 1986 and 2001 (from $43 \%$ to $28 \%$ ). 
Since the beginning of the 20th century, despite the reduced funding, academic lives and careers have been guided, first in the United States and later in other countries, by a "publish or perish" philosophy effects of which have been described as increasingly controversial [15].

\section{Theoretical Framework}

The study is rooted in the human capital theory, which is one of the theories that has always been the subject of bitter criticism in literature. However, [16] asserts that it has "comfortably survived and expanded its influence over other research disciplines” (p. 1). Researchers refined Smith's supposition by categorizing education as an investment good.

In this case, academics are regarded as employees and assets within any university. Having become an asset like any other, the assumption is made that these skills and knowledge can be invested in with the expectation of achieving a rate of return from doing so [17]. As such, individuals invest in human capital such as formal post-secondary education, with the notion that acquiring such human capital enables a person to be more productive. Hence research output and publications become the measures of productivity and efficiency of academics.

\section{Conceptual Framework}

The conceptual framework depicts the relationship between concepts as informed by the literature. Based on the human capital theory wherein academics are seen and assessed as assets to universities and therefore expected to deliver research papers otherwise by default the system eliminates them. Although such a system increase local and international research publications, the pressure mounted on researchers increases the occurrence of academic misconduct such as fraud, ghost papers, plagiarism, and falsifications. Furthermore, much attention and commitment are directed at research and publications while other activities such as related to teaching, learning, and community engagement suffer the brunt of the shift in focus. There is a causal relationship and the framework suggests that until the pressure is reduced, there is a high probability that the process will regenerate itself (Figure 1).

\section{Research Methods and Techniques}

To answer the two research questions a qualitative approach deepened in phenomenology was used to answer the two research questions. Extensive review of literature was also carried out to reinforce this approach. The study population is all universities in China with much emphasis placed on top-ranking universities in China. A summative content analysis was used. The analysis began with key words' search from the top ranking Chinese universities, websites and peer-reviewed journals. Some studies were also selected from Emerald Publishers, SAGE Journals, Taylor and Francis, Springer, and Google Scholar databases. 


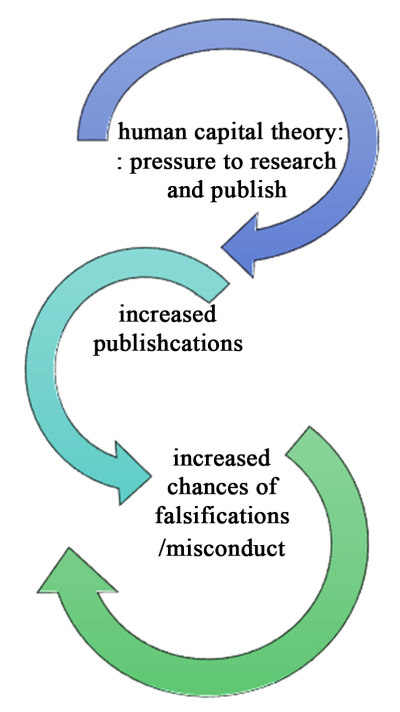

Figure 1. Conceptual framework.

The keywords used in the search were; "academic research in higher learning institutions in China"; challenges and trends in research. Different synonyms and alternate words were also used such as researches in universities as different countries use different terminologies. The articles were collected and checked against descriptors to select the 5 articles that were reviewed. Descriptors checklists included date of publishing, number of citations, and the content addressed. The researcher also drew on her personal experiences of being a student in China and her exposure to higher education institutions. Other additional genuine materials such as the OECD reports were added to provide the background to the study. The data were analyzed using common themes generated from the research questions.

\section{Findings and Discussions}

\subsection{The Current Trends of Research Activities among Academic Staff in Chinese Top Universities}

China's international rankings in research and publications are magnificent [18] despite the language barrier the country is faced with. The involvement of Chinese academics in research activities collaboratively and individually has become evident both nationally and internationally [19]. The Ministry of Education and leaders in Chinese universities are trying a number of different approaches aimed at improving the research performance of academic staff [6]. This could be traced to the period after the end of Cultural Revolution. After the end of the Cultural Revolution, [5] Chinese science began to slowly recover from its slumber (nid). The national policy reforms such as the national policy of "reform and opening up" designed by Chinese leader Deng Xiaoping, could be said were some of the mechanisms which made the environment fertile for progress. In 1973 "the Science Citation Index listed only one paper from China, and by 1979, the Index listed 932 papers" [5]. 
The government periodically invested a lot of money in the 100 Chinese key universities in the 21 st century with the sole purpose of facilitating quality teaching and research development [6]. Project 211 is one of the examples at the State level for education during the Ninth Five-Year Plan and Tenth Five-Year Plan period that the government foresees research and innovation as a central point [20].

These government efforts were not in vain and yielded results as is reflected in the number of scientific publications in the past decade. The data released by the Chinese Science and Technology Information Institute (CSTII) cited by [7] shows that in 2012, international research papers that were published by academics in Chinese higher education institutions amounted to 1.14 million. Comparing this figure with that of 2011 , it can be seen that there is a notable increment of $11.8 \%$.

The increment is not a onetime increment, but a positive trend from the time the government recognized and acknowledge research activities in the institution of higher learning. In 2011, Chinese authors produced 193,733 SCI papers, which is almost about 4 times more than the figure in 2002, [21] and China by then scooped the second-largest SCI producer, behind the United States [22]. In addition to the awards, China was ranked number 9 in the world in terms of publications.

From the history, one can predict the current trends and future trend of research in China, considering that the philosophy of "publish or perish" is much stronger than ever, and that there is a dramatic increase in research expenditure according to [7] the current trends in research asserts international publications have been accepted as indicators of a university's research strength, and is closely related with their rankings on league tables. The university management receives a mandate to increase the number of international publications from the state which is then translated into pressure on academic staff through the introduction of various evaluation and rewards policies.

Research-centered universities are defined as, "Academic institutions committed to the creation and dissemination of knowledge, in a range of disciplines and fields, and featuring the appropriate laboratories, libraries, and other infrastructure that permit teaching and research at the highest possible level", [15] research is regarded as the major indicator for a successful recruitment in any higher learning institution or in some other non-learning institutions as well [22].

In conclusion, it is visible through state funding that the Chinese government has made substantial commitments to science and technology innovations through research. China ranks third when it comes to the state's investment in research, and the government sees this as a key driver of the economy.

Medium and Long-Term Plan for Science and Technology (MLP), the Five-Year Plan for Science and Technology (FYP), and the National Science and Technology Programmes are some of the plans which show that China prioritizes research and innovation. [24] asserts that even the current MLP for 2006-2020 
encourages indigenous innovation in order to raise gross expenditure on $\mathrm{R} \& \mathrm{D}$ (GERD) of the gross domestic product (GDP) to $2.5 \%$ by 2020 from $1.30 \%$ in 2005. Li further clarifies that China is not only rated as the second country with respect to scientific publications and citations, but it as well rated number one in some Pacific research fields such as nanotechnology.

\subsection{The Consequences Arise as a Result of Pressure for Academic Staff to Conduct Research and Publish}

The study finds that research activities have become a major and important intermediating factor in economic development in the twenty-first century, and as such, are increasingly rated as important in the universities contexts. Despite a sharp increase in academic publications in different fields, literature detects negative consequences caused by the "publish-or-perish" philosophy as presented below:

\subsubsection{Serious Shortage of Imaginative and Innovative Research}

The study finds that there is an observable shortage of imaginative and innovative research in management studies despite a sharp increase in academic publications in the field. The study carried by [7] on young academics shows that most the participants were publishing for the sake of publishing, and attaining numbers that were conditions for their contracts they had signed for. Similarly, Adler \& Harzing as cited by [7] believe that the academic assessment system based on quantitative measurement has pushed researchers away from "genuinely fostering" original knowledge (p. 3). [23] points out that research on national innovation system has been a subject of criticism especially for Chinese people. There are ongoing debates on the creativity and innovation among Chinese people commencing from the primary school. Studies such as [11] have linked China's limitation in the practice of radical innovation to a number of factors such as its history, culture, and education system. Furthermore, these studies argue that China's history and culture have kept it from experiencing the openness, opportunity, and cooperation which form the basis of creativity and innovation. Although the same history and culture produced innovative pursuits and products such as the gunpowder, and compass, [11] (p. 46), [23] advised that "China needs to break out of this traditional approach to education if it is to progress beyond incremental and imitative innovation to radical innovation" ( $\mathrm{p}$. 51).

The education system is described by [25] as "Backward" because the content is outdated and the assessment and other evaluation methodologies are old. The system still uses examinations paper systems of testing students thereby contributing poor creativity already from a younger age until university.

The government recognized the dilemma and ongoing discourses and crafted a national legal framework in the 90s to cement the role of universities in the innovation system. [26] clarifies that in1999, the State Council gave its approval to the "Several Provisions on Promoting the Transformation of Scientific and 
Technological Achievements" Framework. The ultimate goal of this framework was to acknowledge and reward the discoverers of new, commercially useful knowledge, and make it easier for research personnel to move back and forth between research and business [27]. As a result of this creativity and innovation were encouraged among researchers.

While the educational foundations of China still in process of being shaken and shifted towards an educational system that must move in the direction of educational critical thinking practices, the shortage of innovative and imaginative research continues as the pressure to publish keeps on mounting on researchers. In concluding this view if academics are publishing for the sake of publishing end up being frustrated and do not look forward to the research results or research outputs.

\subsubsection{Less Priority Being Given to Teaching and Service Roles}

The study finds that as much emphasis is placed on scholarly productivity and the publication among academic staff, less time allocated for other academic activities such as teaching and learning, and community engagement. Literature shows that this has been attributed to the fewer acknowledgments given to academic staff when engaged in other academic activities outside the research process.

\subsubsection{Homogeneity Research and Fabrication of Data}

The pressure to publish is argued to cause homogeneity in research. The researches produced tend to report research results in line with dominant paradigms, so as to maximize the chances of their papers being accepted. A semi-structured interview conducted on seven young faculty members in science and engineering disciplines on this tenure-track contract by [7] most explained that "to increase research productivity that was expectant of them by their employed (the university), they developed a tendency to work on topics and use methods in line with current norms, rather than risking novel practices that might offer significantly original outcomes" (p. 13). [28] adds that homogeneity limit the abilities of researchers to develop a critical stance and threatens the conversation and progress of research in general. In worst-case scenarios, researchers may fabricate data to get their articles published according to [29]. This observation is supported [30] (p. 10) who emphasized that the significance of publication usually reduces the objectivity of the arguments and eventually damage the practice of science this could be true both in a short and long run of research.

\subsubsection{Misconduct in Research}

There is an established relationship in the literature between the pressure for research and publication, and misconduct. The Chinese research misconduct could be traced as far back as the late 90s, when Chinese scientific journals became alarmed about ethical problems with published research, in terms of plagiarism [5]. "Further defining ethical problems to range from plagiarism to un- 
attributed ghost-writing" (p. 3). The pressure to produce results has played a significant role in misconduct problems not only in China but, in other countries including, the U.S.A, South Korea, and Europe [31]. In the case of China, several cases of copying large portions of published papers drew the attention of scientists and the national media [32]. Similarly, in 1997, two cases of wholesale plagiarism and republishing someone else's article under a different name [33] went viral, and commentators partially blamed the system that put pressurized academics to conduct research and publish. The State Council of China cited by [5] echoes that there are two issues responsible China's increasing research misconduct namely, China's flawed research assessment system; and the over-stressing of the required number of publications.

Although the government and the Chinese Association for Science and Technology (CAST) has developed strict measures such as a code of conduct to combat plagiarism and other types of misconduct including copyrights [33] to protect against such misconduct. [34] report that there is quite a number of Chinese research and research from other countries as well that have been retracted due to publication misconducts. These retraction of publications were due to plagiarism and duplicate publication, as well as distrust data or interpretations. Recently in 2017, the Science journal, the Springer Nature publishing company retracted 107 research papers by Chinese authors published in the journal Tumor Biology between 2012 to 2016 [35].

The retraction of publication does not only reflect a waste of time and finance but, it questions the eligibility of the studies which cited such publications.

\section{Conclusion and Recommendations}

The study concludes that China has made progress in terms of research over the past years and the forecast shows a similar positive trend. This is attributed to the government's continued policies and budgetary allocations which prioritize research, innovation, and developmental activities. The high priority on research is proven by the amount spent on research and development, which is incomparable to other developing countries and some developed nations as well. The study finds out that the policies and practices introduced by the government which was meant to motivate more research and publications on the contrary have mounted so much pressure on researchers, especially those in the academic arena. Such pressure has led and might continue to lead to research misconduct such as plagiarism, homogeneity, falsifications of data, ghost's publications and much other unethical research conduct. Additionally, the pressure has led academics to neglect other academic activities that are not acknowledged and do not have any promotional advantages, although of similar importance. While the study finds out that there are some procedures put in place in order to curb the research misconduct, such as the establishment of committees for investigations and development of ethics-related documents, the study suggests that these policies and practices are rather treating the symptoms rather than the root causes of 
research misconduct and negligence of other academic activities. In addition the positive enforcement used by institutions may suppress the limited research and publication, but it does not permanently eliminate such actions. Consequently, these superficial treatments pose a threat because such misconducts may still manifest in ways other than the ways identified.

Against this backdrop, there is a need to treat the identified cause which is the "pressure", in order to reduce and avoid future research misconduct, and encourage researchers to engage in research on free will and curiosity, subsequently cultivating a research culture that encourages ethical behavior.

Henceforth, the study recommends the following to the government which is the custodian of higher education and research and publication in particular:

- It should reexamine its policies and practices that encourage quality over quantity.

- The focus should be directed on innovation, it is far more beneficial and important than counting numbers of recognized publications by a university or by an individual. Academics can submit a portfolio of which they can submit two best articles and write a report to defend why they think their articles deserve to be evaluated for salary, funding applications, and future promotions. Evaluating academics on their best paper and self-evaluation report will not only motivate researchers to commit to innovative research which is more challenging and unique, but researchers will have ample time to redistribute and attend to other activities of equal importance to their careers and work.

The study further recommends that researchers consider expanding this study to look for alternative solutions to reduce the pressure of research and publications.

\section{Conflicts of Interest}

The author declares no conflicts of interest regarding the publication of this paper.

\section{References}

[1] Chem, C. (2015) A Study Showing Research Has Been Valued over Teaching in Higher Education. Journal of the Scholarship of Teaching and Learning, 15, 15-32. https://files.eric.ed.gov/fulltext/EJ1064434.pdf

[2] Gu, J.M., Li, X.P. and Wang, L.H. (2018) Higher Education in China. Springer Nature, Switzerland. https://doi.org/10.1007/978-981-13-0845-1

[3] Garfield, E. (1996) Citation Analysis as a Tool in Journal Evaluation. Science, 178, 471-479. https://doi.org/10.1126/science.178.4060.471

[4] Rosenberg, N. and Mowery, D. (1993) Technology and the Pursuit of Economic Growth. Cambridge University Press, Cambridge, England. http://garfield.library.upenn.edu/classics1993/A1993LF84000001.pdf

[5] Resnik, D. and Zeng, W. (2009) Research Integrity in China: Problems and Prospects. Developing World Bioethics, 10, 164-171. 
https://www.ncbi.nlm.nih.gov/pmc/articles/PMC2891906/

[6] Kang, C., Wang, G., Shi, M. and Sun, F. (2014) Research Trend on Higher Education in China for the Past Ten Years. International Journal of Educational Management, 28, 319-339.

https://www.emerald.com/insight/content/doi/10.1108/IJEM-04-2013-0059/full/ht $\underline{\mathrm{ml}}$

[7] Tian, M., Su, Y. and Ru, X. (2016) Perish or Publish in China: Pressures on Young Chinese Scholars to Publish in Internationally Indexed Journals. Publications, 4, 9. https://pdfs.semanticscholar.org/8610/49291c9e6884300220465b668045975a8d6f.pd f

[8] Fawzi, H. and Al-Hattami, A. (2017) Faculty Production of Research Papers: Challenges and Recommendations. International Journal of Humanities and Social Science, 7, 221-228.

https://www.ijhssnet.com/journals/Vol 7 No 2 February 2017/29.pdf

[9] Bouchikhi, H. and Kimberley, J. (2001) It's Difficult to Innovate: The Death of the Tenured Professor and the Birth of the Knowledge Entrepreneur. Human Relations, 54, 77-84. https://journals.sagepub.com/doi/10.1177/0018726701541010

[10] OECD (2015) Frascati Manual 2015: Guidelines for Collecting and Reporting Data on Research and Experimental Development. The Measurement of Scientific, Technological and Innovation Activities, OECD Publishing, Paris. https://www.oecd.org/sti/inno/Frascati-Manual-2015-Flyer-EN.pdf

[11] Beijing Bureau of Statistics (2015) Beijing Economic and Social Development Statistical Bulletin 2014. https://www.oecd.org/china/Education-in-China-a-snapshot.pdf

[12] Johnes, J. and Yu, L. (2008) Measuring the Research Performance of Chinese Higher Education Institutions Using Data Envelopment Analysis. China Economic Review, 19, 679-696.

[13] Xue, L. (2006) Universities in China's National Innovation System. UNESCO Forum on Higher Education, Research and Knowledge.

[14] Lancrin, S.V. (2009) What Is Changing in Academic Research? Trends and Prospects. In: Higher Education to 2030, Volume 2: Globalisation, OECD, Paris.

[15] Altbach, P.G. (2013) Advancing the National and Global Knowledge Economy: The role of Research Universities in Developing Countries. Studies in Higher Education, 38, 316-330. http://citeseerx.ist.psu.edu/viedoc/dowoad?doi=10.1.1.844.464\&rep=rep1\&type=pdf

[16] Emrullah, T. (2014) Human Capital Theory: A Holistic Criticism. Review of Educational Research, 84, 411-445.

[17] Kjelland, J. (2008) Economic Returns to Higher Education: Signaling v. Human Capital Theory. The Park Place Economist, 16, 1-10.

[18] Hugo, H. and Shen, W.Q. (2019) Current and Future Challenges of the Chinese Research System. Journal of Higher Education Policy and Management.

[19] Reddy, K.S., Xie, E. and Tang, Q.Q. (2016) Higher Education, High-Impact Research, and World University Rankings: A Case of India and Comparison with China. Pacific Science Review B: Humanities and Social Sciences, 2, 1-21. https://www.researchgate.net/publication/310593015 Higher education high-impa ct research and world university rankings A case of India and comparison $\mathrm{w}$ ith China/citation/download

[20] China Education and Research (2001) Project 211, a Brief Introduction. http://www.edu.cn/highedu 1413/index.shtml 
[21] Qiu, J. (2015) Safeguarding Research Integrity in China. National Science Review, 2, 122-125.

[22] Liu, X. and White, S. (2001) Comparing Innovation Systems: A Framework and Application to China's Transitional Context. Research Policy, 30, 1091-1114.

[23] Johnson, H.A. and Weiss, J.W. (2008) A Stage Model of Education and Innovation Type in China: The Paradox of the Dragon. Journal of Technology Management in China, 3, 66-81.

[24] Liu, L. (2009) Research Priorities and Priority-Setting in China, Tsinghua University, Beijing, Vinnova-Verketför Innovations System/Swedish Governmental Agency for Innovation System.

[25] Zhao, X. and Zhao, X. (2012) Another Way to Develop Chinese Students' Creativity: Extracurricular Innovation Activities Normal University, Mianyang. US-China Education Review B, 6, 566-571.

[26] Wu, W. (2010) Higher Education Innovation in China. The Journal of Technology Transfer.

[27] Suttmeier, P. and Cao. C. (1999) China Faces the New Industrial Revolution: Achievement and Uncertainty in the Search for Research and Innovation Strategies. Asian Perspective, 23, 153-200.

[28] Lukka, K. and Mouritsen, J. (2002) Homogeneity or Heterogeneity of Research in Management Accounting? European Accounting Review, 11, 805-811.

[29] Fanelli, D. (2012) Negative Results Are Disappearing from Most Disciplines and Countries. Scientometrics, 90, 891-904.

[30] Lawrence, P.A. (2008) Lost in Publication: How Measurement Harms Science. Ethics in Science and Environmental Politics, 8, 1-3. https://www.int-res.com/articles/esep2008/8/e008p009.pdf

[31] Shamoo, A. and Resnik, D. (2009) Responsible Conduct of Research. Oxford University Press, New York.

[32] Xiguang, L. and Lei, X. (1996) Chinese Researchers Debate Rash of Plagiarism Cases. Science, $274,337$.

[33] Wang, J. (1999) Chinese Journals Pledge Crackdown. Science, 283, 1427.

[34] Zhang, M. and Grieneisen, M.L. (2013) The Impact of Misconduct on the Published Medical and Nonmedical Literature, and the News Media. Scientometrics, 96, 573-587.

[35] Chen, S. (2017)

https://www.scmp.com/news/china/society/article/2089973/science-journal-retracts -107-research-papers-chinese-authors 